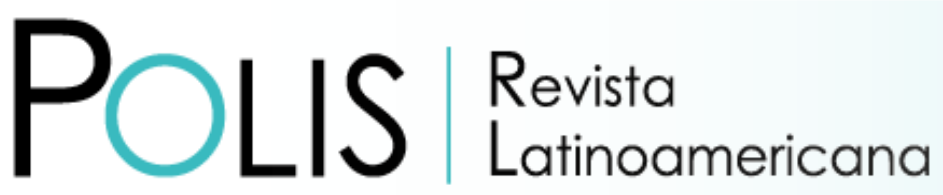

V20 | N59 | 2021

DOI: $10.32735 /$ S0718-6568/2021-N59-1463

\title{
Hibridação e tradução cultural em tempos de globalização: reflexões sobre o artesanato contemporâneo em perspectiva territorial
}

\author{
Carolina luva de Mello \\ Universidade Federal de Santa Maria, Santa Maria, Brasil \\ Email: carolinaiuva@gmail.com \\ José Marcos Froehlich \\ Universidade Federal de Santa Maria, Santa Maria, Brasil \\ Email: jmarcos.froehlich@gmail.com
}

Recibido:27.03.2020 | Aceptado: 04.01.2021

\begin{abstract}
Resumo: Dinâmicas globalizantes têm intensificado os contatos de experiências e fricções entre culturas até então distantes, promovendo processos de hibridação em escala territorial. Esse contexto interfere na produção artesanal, cuja representação se aproxima da noção de tradução cultural proposta por Bhabha. Neste artigo analisamos as possibilidades e práticas de hibridação recorrentes nas expressões de valores, formas e saberes de artesãos quando em interações com universos e códigos simbólicos diversos e mais amplos. A partir do método fenomenológico, empreendemos pesquisa empírica junto à Costa Doce, território no Sul do Brasil, no qual a prática artesanal vem sofrendo hibridações no intuito de se tornar expressão de identidade territorial. As considerações finais apontam que os processos de hibridação, nos quais se busca vincular o artesanato à expressão identitária dos territórios, podem ser considerados estratégias relevantes de continuidade da prática artesanal enquanto alternativa econômica não dissociada do simbólico, desde que sejam conduzidas pelos próprios artesãos.
\end{abstract}

Palavras-chave: Globalização; território; hibridação; artesanato; tradução cultural.

\section{Hibridación y traducción cultural en tiempos de globalización: reflexiones sobre artesanías contemporáneas en perspectiva territorial}

Resumen: La dinámica globalizadora ha intensificado los contactos de experiencias y fricciones entre culturas hasta ahora distantes, promoviendo procesos de hibridación a escala territorial. Este contexto interfiere con la producción artesanal, cuya representación se acerca a la noción de traducción cultural propuesta por Bhabha. En este artículo analizamos las posibilidades y prácticas de hibridación recurrente en la expresión de valores, formas y conocimiento de los artesanos al interactuar con universos diversos y códigos simbólicos 
más amplios. Con base en el método fenomenológico, llevamos a cabo una investigación empírica en Costa Doce, un territorio en el sur de Brasil, en el que la práctica artesanal ha sufrido hibridaciones para convertirse en una expresión de identidad territorial. Las consideraciones finales señalan que los procesos de hibridación, en los que se busca vincular la artesanía con la expresión de identidad de los territorios, pueden considerarse estrategias relevantes para la continuidad de la práctica artesanal como una alternativa económica no disociada de lo simbólico, siempre y cuando sean conducidas por los propios artesanos.

Palabras clave: Globalización; territorio; hibridación; artesanías; traducción cultural.

\title{
Hybridization and Cultural Translation in Times of Globalization: Reflections on Contemporary Crafts in Territorial Perspective
}

\begin{abstract}
Globalizing dynamics have intensified the contacts of experiences and frictions between cultures hitherto distant, promoting hybridization processes on a territorial scale. This context interferes with artisanal production, whose representation is close to the notion of cultural translation proposed by Bhabha. In this article we analyze the possibilities and practices of recurrent hybridization in the expression of values, forms and knowledge of craftsmen when interacting with diverse and broader universes and symbolic codes. Based on the phenomenological method, we undertook empirical research in Costa Doce, a territory in southern Brazil, in which artisanal practice has undergone hybridizations in order to become an expression of territorial identity. The closing remarks point out that the hybridization processes, in which one seeks to link handicrafts to the identity expression of the territories, can be considered relevant strategies for the continuity of the handicraft practice as an economic alternative not dissociated from the symbolic, as long as they are conducted by the craftsmen themselves.
\end{abstract}

Keywords: Globalization; Territory; Hybridization; Handicrafts; Cultural translation.

\section{Como citar este artículo:}

Iuva de Mello, C y Marcos Froehlich,J. (2021). Hibridação e tradução cultural em tempos de globalização: reflexões sobre o artesanato contemporâneo em perspectiva territorial. Polis Revista Latinoamericana, 20 (59), 203-222. doi: http://dx.doi.org/10.32735/S0718-6568/ 2021-N59-1463

\section{Introdução}

A expansão da globalização facilitou a massificação de processos econômicos e simbólicos a partir da criação de um imaginário coletivo 'internacional popular' (Ortiz, 2013). Porém, em paralelo e como que em um movimento reativo, a preocupação com as identidades sociais passou a permear discussões em diversas áreas do conhecimento. Em uma perspectiva antropológica, a identidade consiste no 'pertencimento' a um grupo, que compartilha signos e significados reconhecidos por todos e reivindicados na interação com a alteridade. Entre as diversas produções identitárias contemporâneas, aquela catalisada 
pela variável territorial tem se destacado devido à importância que lhe tem sido atribuída nas estratégias que se tecem em nome do desenvolvimento (Abramovay, 2003; Froehlich, 2012; Favareto, 2015).

No âmbito dos processos de globalização as disputas por territorializações e territorialidades são demarcadas por interações e trocas culturais cada vez mais frequentes entre conjugações de interesses e conhecimentos diferentes. Canclini (2013) vai denominar de hibridação aos processos socioculturais nos quais estruturas e práticas que existiam de forma separada, combinam-se em novas estruturas, práticas e objetos híbridos, que, por sua vez, fundem-se novamente, resultando em um processo incessante e heterogêneo chamado por Stross (1999) de 'ciclo de hibridação'.

A noção de hibridação vem sofrendo diferentes críticas ao longo do tempo, sendo a mais comum a que o acusa de favorecer a expansão capitalista, pois contribuiria para o aumento no consumo de determinados bens culturais (Kern, 2004). Porém, Bernd (2004) ressalta seu aspecto positivo, especialmente quando entendido como um processo de ressimbolização, ou seja, mediante a tensão entre elementos díspares que gera novos objetos culturais que correspondem a tentativas de tradução ou de inscrição subversiva da cultura de origem em outra. Ressaltamos que uma teoria não ingênua da hibridação é inseparável de uma consciência crítica de seus limites. Assim, podemos associar a hibridação com processos de dominação, resistência e tradução que promovem resultados heterogêneos para grupos sociais diversos (Canclini, 2013).

Os processos de hibridação são presenciados com frequência no artesanato contemporâneo, especialmente quando atributos de identificação com o território são ressaltados ou conferidos aos artefatos, a partir da interação com profissionais do design, para que se insiram na arena de produção-circulação-consumo de artefatos culturais propiciada pelos fluxos turísticos nos territórios. Nesse contexto, nossa análise e reflexão se detêm aqui sobre as possibilidades e práticas de hibridação recorrentes que tem permitido a grupos de artesãos expressar seus valores, formas e saberes em interação com universos e códigos simbólicos diversos e mais amplos. Efetuamos estudo' de base empírica junto ao território da Costa Doce, território no extremo sul do Brasil, onde a prática artesanal vem sofrendo hibridações no intuito de se tornar expressão de identidade territorial nas estratégias de projeção identitária em curso no território (Mello e Froehlich, 2015).

Este artigo está estruturado em cinco seções. Inicialmente, apresentamos um aporte conceitual acerca dos temas hibridação e tradução cultural no contexto globalizado contemporâneo com o intuito de subsidiar as discussões posteriores. Na sequência, discorremos

1 O estudo em questão, de caráter qualitativo, foi pautado pelo método fenomenológico com a adoção de uma abordagem de pesquisa interpretativista. O percurso metodológico compreendeu coleta e sistematização dos dados secundários seguido de entrevistas semiestruturadas com informantes qualificados envolvidos no contexto do artesanato no território da Costa Doce. Para mais informações, ver Mello (2016). 
sobre como os processos de hibridação no artesanato vem se delineando em diferentes territórios. E, por fim, são tecidas considerações relativas à interação entre as noções teóricas e as evidências empíricas apresentadas.

\section{Hibridação e tradução cultural na globalização}

A compressão espaço-tempo ${ }^{2}$ possibilitou a troca de experiências e visões de mundo entre civilizações e culturas até então distantes. Esse novo cenário suscitou a preocupação por parte daqueles que acreditam que a globalização pode ameaçar a diversidade cultural por meio da homogeneização das identidades (Radcliffe, 2006). Porém, por mais que a globalização desloque as identidades centradas e fechadas de uma cultura nacional, ela tem, ao mesmo tempo, um efeito pluralizante sobre as identidades, produzindo novas posições de identificação, mais políticas e plurais; menos fixas e trans-históricas.

"Algumas identidades gravitam ao redor daquilo que Robins chama de 'Tradição', tentando recuperar sua pureza anterior e recobrir as unidades e certezas que são sentidas como tendo sido perdidas Outras aceitam que as identidades estão sujeitas ao plano da história, da política, da representação e da diferença e, assim, é improvável que elas sejam outra vez unitárias ou 'puras'; e essas, consequentemente, gravitam ao redor daquilo que Robins (seguindo Homi Bhabha) chama de 'Tradução'" (Hall, 1999, p. 87).

A noção de tradução descreve as formações de identidade que interconectam e ultrapassam as fronteiras das diferenças. O processo de tradução é um processo de interpretação, de relocalização, que pressupõe a existência de um estado anterior. Porém, diferentemente da apropriação, a tradução é uma relação que não atribui imediatamente um valor padrão a algum tipo de 'original' anterior (Asega et al., 2017). A tradução cultural, para Bhabha (1990), é um processo ambivalente pelo qual se demanda que as culturas revejam seus próprios sistemas de referencia, normas e valores. Ou seja, as identidades não são entidades imutáveis, mas processos incessantes de construção e reconstrução dos imaginários sociais (Beired e Barbosa, 2010).

Nesse contexto, Bhabha (2013) questiona a própria validade da cultura como símbolo, construção aparentemente universal e desvinculada de qualquer contexto, e defende a noção da cultura como signo, localizada dentro de um contexto específico, comprometida com um sistema ideológico, envolto em uma arena de conflitos. As condições discursivas da enunciação dão flexibilidade aos signos, de modo que estes possam ser traduzidos, ou seja, lidos de outro modo. Para Bhabha (2013), isso faz com que as reinvindicações hierárquicas de originalidade ou 'pureza' inerentes às culturas sejam insustentáveis, mesmo antes de se recorrer a instâncias históricas empíricas que demonstram seu hibridismo.

2 A compressão espaço-tempo é uma característica do atual estágio do capitalismo, onde "os horizontes temporais da tomada de decisões privada e pública se estreitaram, enquanto a comunicação via satélite e a queda dos custos de transporte possibilitaram cada vez mais a difusão imediata dessas decisões num espaço cada vez mais amplo e variegado" (Harvey, 2012, p. 140). 
Desse modo, a questão não é como preservar tradições ou identidades inalteradas, mas investigar como elas estão se transformando, como interagem com as forças da globalização que promovem processos de encontros, interações e trocas culturais cada vez mais frequentes. Embora existam diversas denominações para se referir a essa nova situação intercultural, Canclini (2013) opta pelo termo hibridação, pois não limita as mesclas interculturais à raça, como ocorre com o termo 'mestiçagem', nem a fusões religiosas ou de movimentos simbólicos tradicionais, onde normalmente se aplica o termo 'sincretismo'. Porém, o conceito de hibridação vem sofrendo diferentes críticas ao longo do tempo, sendo a mais comum a que o acusa de ser um "sucedâneo para o aumento de consumo de determinados bens culturais, favorecendo a expansão capitalista sobre o globo" (Kern, 2004, p. 62). Segundo Bernd (2004), é preciso levar em consideração que o conceito pode encobrir certo imperialismo cultural prestes a apropriar-se de elementos de culturas minoritárias para reutilizá-las a partir dos paradigmas de aceitabilidade das culturas hegemônicas. Contudo, a própria autora ressalta o aspecto positivo do termo, referindo-se a ele como um processo de ressignificação simbólica:

"Se por híbrido queremos nos referir a um processo de ressimbolização em que a memória dos objetos se conserva e em que a tensão entre elementos díspares gera novos objetos culturais que correspondem a tentativas de tradução ou de inscrição subversiva da cultura de origem em uma outra cultura, então estamos diante de um processo fertilizador" (Bernd, 2004, p. 100-101).

Para Canclini (2008) a hibridação, favorecida pela globalização, não é um simples processo de homogeneização, mas de confrontação e diálogo, de reordenamento das diferenças e desigualdades, sem suprimi-las. Apesar de ter escolhido apresentar os casos prósperos e inovadores de hibridação, o autor compreende que a hibridação pode ocorrer em meio a sistemas de produção e consumo que operam como coações. Assim, Canclini (2013) concebe a existência de relações de poder nos processos de hibridação, todavia, não a concebe como uma via de mão única, do hegemônico para o subalterno, mas sim como processos indissociáveis de dominação e resistência que ocasionam resultados heterogêneos para grupos sociais diversos.

"[A hibridação] é um processo através do qual se demanda das culturas uma revisão de seus próprios sistemas de referência, normas e valores, pelo distanciamento de suas regras habituais ou 'inerentes' de transformação. Ambivalência e antagonismo acompanham cada ato de tradução cultural, pois o negociar com a 'diferença do outro' revela uma insuficiência radical de nossos próprios sistemas de significado e significação" (Bhabha, 1997 como citado em Hall, 2003, p. 75).

Além da crítica previamente exposta, a noção de hibridação foi contestada por ser um conceito transferido da biologia, acarretando perda de univocidade científica. Porém, Canclini (2013) ressalta que as ciências sociais sempre importaram noções de outras disciplinas que não foram invalidadas por suas condições de uso na ciência de origem. O que deve ser avaliado é a fecundidade explicativa do termo, possibilitando melhor compreensão de algo que até então permanecia precariamente explicado (Canclini, 2013). 
Na visão de Bhabha (2013), o conceito é positivo, pois nega o essencialismo de uma cultura anterior ou originária, de modo que todas as formas de cultura estão constantemente em um processo de hibridação. Para o autor, sua importância não reside em poder traçar dois momentos originários a partir dos quais surge um terceiro, mas no entre-lugar, o 'terceiro espaço' resultante da hibridação que desloca as histórias que o constituem e possibilita o surgimento de novas posições, estabelecendo novas estruturas e iniciativas políticas (Bhabha, 1990). Na contemporaneidade, o trabalho fronteiriço da cultura "cria uma ideia do novo como ato insurgente de tradução cultural", o passado é renovado, reconfigurado "como um entre-lugar contingente, que inova e interrompe a atuação do presente" (Bhabha, 2013, 29). Ao reencenar o passado, temporalidades culturais incomensuráveis são introduzidas na invenção da tradição ${ }^{3}$, afastando qualquer acesso imediato a uma tradição recebida (Bhabha, 2013; Hobsbawm, 2012).

O terceiro espaço, conforme denomina Bhabha (2013), é resultante da hibridação entre identidades situadas assimetricamente em relação ao poder, porém, não é determinado unilateralmente pela identidade hegemônica. "Claro que as relações não costumam ser igualitárias, mas é evidente que o poder e a construção do acontecimento são resultado de um tecido complexo e descentralizado de tradições reformuladas e intercâmbios modernos, de múltiplos agentes que se combinam" (Canclini, 2013, p. 261). A hibridação, portanto, não implica necessariamente sujeição do tradicional ao moderno, ou do subalterno ao hegemônico, mas uma (re)criação cultural que pode ou não estarinscrita em relações assimétricas (Mello, 2016).

Frequentemente a hibridação surge da criatividade individual e/ou coletiva, produzindo novas formas de cultura (Hall, 1999; Canclini, 2013). Desse modo, a criatividade é um fator relevante para a noção de hibridação, pois possibilita a criação de novos produtos, significados e sínteses culturais. Para Stross (1999), os híbridos, em particular no domínio cultural, são muitas vezes criados para cumprir funções ambientalmente sancionadas, para preencher as necessidades contextuais, ou para aproveitar as oportunidades criadas pelas novas condições de produção e mercado, dinâmica vislumbrada com frequência no artesanato brasileiro.

\section{Artesanato: hibridação e projeção identitária em perspectiva territorial}

O artesanato 4 é um dos meios mais importantes de expressão da identidade de um grupo social, pois através dele valores coletivos são fortemente representados. Desde os primórdios da vida social, a atividade artesanal desempenhou um papel de destaque nas sociedades (Mello e Froehlich, 2016). Porém, a expansão da produção industrial no decorrer do século XX fez com que muitos acreditassem no desaparecimento progressivo da produção artesanal

3 "Por 'tradição inventada' entende-se um conjunto de práticas, normalmente reguladas por regras tácita ou abertamente aceitas; tais práticas de natureza ritual ou simbólica visam involucrar certos valores e normas de comportamento através da repetição, o que implica, automaticamente, uma continuidade em relação ao passado. Aliás, sempre que possível tenta-se estabelecer continuidade com um passado histórico apropriado [...]" (Hobsbawm, 2012, p. 9).

4 Neste estudo será utilizada a definição de artesanato apresentada pelo World Crafts Council (2012): toda atividade produtiva que resulte em artefatos acabados feitos manualmente ou com a utilização de meios tradicionais ou rudimentares, com habilidade, destreza e criatividade. 
de bens. Com efeito, "pareceu a muitos estudiosos, nos albores da industrialização, que a fábrica acabaria fatalmente por absorver a oficina [...] e o artesanato, típico de uma era superada pelo capitalismo e pela indústria, passaria a atividade fóssil e marginal" (Rios, [196-], p. 11).

Contrariando os prognósticos negativos, o fazer artesanal se mantém presente na sociedade contemporânea. "Artefatos feitos à mão estão agora desempenhando um papel considerável no mercado mundial. Peças do Afeganistão e do Sudão estão sendo vendidas nas mesmas lojas que os mais recentes produtos dos estúdios de design de fábricas italianas e japonesas" (Paz, 2006, n.p.). A proliferação do artesanato na internet e a sua presença cada vez mais constante nas exposições de design e nas galerias de arte evidenciam uma superação da percepção do objeto artesanal como algo antiquado ou tradicional (Black e Burisch, 2010).

Os frequentadores da Semana de Design de Milão e do London Design Festival, as duas principais arenas internacionais da área do design, têm se deparado cada vez mais com exposições de objetos feitos à mão [...]. As lojas de museus internacionais têm reduzido o número de gadgets industrializados em favor de objetos que resultam de empreendedorismo de base comunitária (Borges, 2020, n.p.).

Segundo a folclorista Vera de Vives (1983), essa expansão no interesse pelo artesanato surgiu inicialmente da rebelião dos jovens habitantes de países desenvolvidos contra a dominação e homogeneização da indústria e a desumanização do trabalho. Para Mignosa e Kotipalli (2019), na atualidade está em curso uma nova onda de revitalização do artesanato, impulsionada pela disseminação do movimento 'faça você mesmo', e cuja ênfase se encontra no potencial econômico da atividade artesanal em tempos de crise ${ }^{5}$.

Porém, apesar de a prática artesanal se manter presente na atualidade, não se pode negar que muitos dos artefatos artesanais que tradicionalmente buscavam satisfazer determinadas necessidades práticas tiveram, com a expansão das indústrias, suas funções utilitárias enfraquecidas. Desse modo, concordamos com D'ávila (1983) quando ele afirma que o artesanato passou a ter mais significado e valor pelas suas referências culturais e simbólicas do que por seu valor de uso. Portanto, na contemporaneidade, a crescente importância ${ }^{6}$ atribuída ao artesanato se deve especialmente aos seus atributos simbólicos, que expressam manifestações identitárias relacionadas com o território da comunidade que os gerou.

Nas atuais dinâmicas globais, permeadas por processos indissociáveis de globalização e territorialização, cabe visualizar os territórios como campos de disputa onde os atores buscam, por intermédio de variados recursos materiais e culturais, imprimirem sentidos e interpretações, tomarem posições, carrearem apoios, produzirem e legitimarem consensos

5 No Brasil, o setor do artesanato vem crescendo a cada ano. Em 2019, representou 3\% do Produto Interno Bruto nacional e empregou oito milhões de pessoas, das quais, $87 \%$ mulheres (Serviço de Apoio às Micro e Pequenas Empresas, 2019).

6 No Brasil, por exemplo, o setor do artesanato vem crescendo a cada ano. Em 2019, representou 3\% do Produto Interno Bruto nacional e empregou oito milhões de pessoas, das quais, $87 \%$ mulheres (Serviço de Apoio às Micro e Pequenas Empresas, 2019). 
favoráveis a si (Brandão, 2007). Em nome do reconhecimento do território e do seu desenvolvimento, busca-se a construção de uma imagem identitária do território, e, a projeção de tais identidades territoriais, torna-se objetivo estratégico e expressão de disputa (Bauman, 2008). A identidade territorial, portanto, tem se constituído como estratégia capaz de promover sentidos acerca do território e vem sendo continuamente disputada em narrativas que se tecem em nome do desenvolvimento. Assim como a cultura não é fixa, o território pode possuir identidades múltiplas, resultados e fontes de contradição (Castells, 1999).

A compreensão de território utilizada neste artigo é a relacional, na qual o poder ${ }^{7}$ está no centro da análise e a territorialidade é formada pelas relações sociais que se estabelecem nos territórios (Raffestin, 1993; Haesbaert, 1997). Para Soares Jr. e Santos (2018), a demarcação ou delimitação de um espaço geográfico, por si só, não caracteriza a existência de um território. Este só se constitui quando indivíduos ou grupos exercem sua territorialidade, isto é, buscam atingir, influenciar ou controlar pessoas, fenômenos e relacionamentos (Sack, 1986). Assim, é possível afirmar que o território importa, não como conjunto físico, mas "enquanto expressão e produto das interações que os atores protagonizam. O território, nestas circunstâncias, é proximidade, atores, interações" (Reis, 2015, p. 109). Essa abordagem reconhece o território como uma construção social, compreendido pela sua dimensão valorativa e resultante da identificação e da mobilização dos atores sociais em um dado espaço geográfico.

Portanto, além da dimensão de caráter político-disciplinar, o território envolve uma dimensão simbólica, por meio de uma "identidade territorial atribuída pelos grupos sociais, como forma de 'controle simbólico' sobre o espaço onde vivem" (Haesbaert, 1997, p. 42). E, em muitos territórios, o artesanato passou a desempenhar um papel de diferenciação simbólica. Narrativas passaram a ser criadas, reconstruídas ou evocadas para revestir os artefatos feitos à mão de certa 'aura' (Benjamin, 1987) em oposição aos objetos impessoais da produção em massa. Nesse contexto, o artesanato "não tem mais função e sim uma virtude: é um signo" (Baudrillard, 2009, p. 90), e os esforços empreendidos com o objetivo de reivindicar sua inserção na arena de produção-circulação-consumo de artefatos culturais vinculados aos territórios acabam implicando em vários tipos de singularizações, muitas vezes associadas a (re)construções ou (re)semantizações de tradições inventadas (Kopytoff, 2008; Hobsbawm, 2012).

A crescente aproximação dos artesãos a profissionais da área do design visando sua singularização é a forma mais evidente de hibridação no artesanato contemporâneo, e suscita diferentes perspectivas. Para Leite (2005), existem dois grandes eixos teóricos que podem ser denominados como tradicionalista e mercadológico. A visão tradicionalista, segundo Leite (2005), entende o artesanato como uma arte de fazer tradicional que deve ser preservada sem qualquer alteração. Já a perspectiva mercadológica defende a inserção do artesanato nos mercados simbólicos, tornando os artesãos, em muitos casos, apenas mão de obra para produtos concebidos por outros. Todavia, a visão do artesanato não pode ser

7 No sentido que lhe dá Foucault (1991; 1995), da capacidade de agir sobre as ações de outros. 
limitada nem por seu aspecto simbólico, buscando-se simplesmente preservar a tradição cultural, "haja vista o êxodo dos jovens e a persistente miséria daqueles que permanecem em povoados inalterados", nem por seu aspecto econômico, "através da total mercantilização e industrialização dos produtos artesanais", pois isto acarretaria em descaracterização dos padrões culturais dos artesãos (Canclini, 1983, p. 140).

Para além dessas perspectivas dicotômicas está a posição do designer atuando como mediador entre as demandas mercadológicas por bens simbólicos e a produção artesanal (Noronha, 2011; Lima 2011). Segundo Borges (2011) a aproximação do design e do artesanato se faz importante especialmente devido ao impacto social e econômico que gera. Contudo, ressalta que o trabalho resultante deste intercâmbio deve ter significado e relevância para os artesãos, de modo que possa ser continuado após a atuação do designer (Borges, 2011), visto que, sendo a prática artesanal composta por processos que se inserem reflexivamente no contexto de sua produção e se refletem nos modos de vida de quem os produz, são os artesãos que devem decidir quais inovações e alterações estéticas podem ser aceitas e quais se opõem aos seus interesses (Leite, 2005; Canclini, 1983). Portanto, inovações estéticas na produção do artesanato podem facilitar e assegurar sua reprodutibilidade, ainda que em um estado alterado da tradição, desde que em conformidade com os anseios dos artesãos.

O projeto 'Editoria, design, artesanato \& indústria', desenvolvido em Portugal, encontra-se em conformidade com a posição de Leite (2005). O projeto busca, através da aproximação entre designers e artesãos, reinterpretar os ofícios tradicionais locais que ainda são significativos no território, reinventando-os em diálogo com as demandas do mercado global (Albino, 2017). A ação, segundo Albino (2017), é considerada importante para a valorização do território, pois os artefatos desenvolvidos em processos de cocriação entre designers e artesãos são reveladores dos valores identitários do território, criando um diálogo entre o ancestral genuíno das técnicas tradicionais e os novos desejos de uma existência urbana contemporânea.

Nesse contexto, uma organização internacional que merece destaque é a Organização das Nações Unidas para a Educação, a Ciência e a Cultura (UNESCO), pois além de promover atividades de formação e promoção da prática artesanal em diferentes países do globo, a entidade procura demonstrar às autoridades governamentais a prioridade que o artesanato merece ter nos programas nacionais de desenvolvimento (UNESCO, 2017). Em 2005, a UNESCO publicou um guia prático intitulado 'Encuentro entre Diseñadores y Artesanos' com o objetivo de propor diretrizes para que a interação entre designers e artesãos resulte em um relacionamento equilibrado e mutuamente benéfico aplicável a um amplo espectro do setor artesanal mundial (UNESCO, 2005). Na publicação em questão são apresentados estudos de caso de diferentes regiões da Índia e da Colômbia, demonstrando que modelos de intervenções podem ser desenvolvidos para diferentes propósitos, seja para revitalizar o artesanato que está desaparecendo ou para desenvolver novos produtos que gerem renda em modos de vida diversos (UNESCO, 2005). 
As experiências na Índia demonstraram que a hibridação ocorrida no design das peças, apesar de favorável para um incremento da remuneração dos artesãos, só se torna realmente eficaz e útil para os participantes quando fica estabelecida a relação entre a criação de novos artefatos e a melhoria da qualidade de vida dos artesãos, ou seja, quando os artesãos são participantes ativos da ação e não beneficiários passivos das contribuições dos designers (UNESCO, 2005). Na Colômbia, desde 1964 a entidade Artesanías de Colombia, vinculada ao Ministério do Comércio, Indústria e Turismo, vem promovendo ações com o objetivo de dignificar o artesanato e consolidar a imagem do setor e da identidade nacional. Visando alcançar esse objetivo, estabeleceu Laboratórios de Design em diferentes regiões do país que contam com a participação de representantes do setor produtivo e da comunidade acadêmica para prestar assessoria e fortalecer o setor artesanal colombiano. Com as experiências dos Laboratórios de Design, a entidade pode estabelecer diretrizes para a interação entre designers e artesãos, reforçando a importância de se reconhecer o artesão como um parceiro criativo e não como um mero trabalhador qualificado (UNESCO, 2005).

Ainda no contexto da América do Sul, o Programa de Artesanía da Escola de Design da Universidade Católica do Chile, em atuação desde a década de 1980, vem concentrando seus esforços na promoção e divulgação do artesanato no Chile, abordando integralmente o trabalho do setor artesanal e estabelecendo-se como referência nacional e internacional (Escuela de Diseño, [20--]). O Programa promove oficinas nas quais os alunos aprendem diretamente com o artesão e juntos projetam obras originais; esse diálogo entre artesãos e designers vem resultando em peças artesanais tão inovadoras quanto reconhecíveis em sua tradição (Paz, 2015).

Ressaltamos que apesar da interação com designers ser uma das formas mais evidentes de hibridação no artesanato contemporâneo, ela não é exclusiva. O artesanato, assim como qualquer outro produto cultural, é dinâmico e comumente se modifica para atingir novos destinatários, adaptando motivos tradicionais às tendências estéticas atuais, ou até mesmo altera sua função, despojando-se do simbolismo original para ampliar seu uso a qualquer consumidor (Paz, 2015). A profusão das tecnologias da informação e comunicação no contexto globalizado vem propiciando a hibridação no artesanato mesmo em locais onde inexistem ações de aproximação com profissionais do design. A televisão, a internet e as revistas especializadas em artesanato possuem um papel relevante nesse cenário. Vargas (2016), ao discorrer sobre o artesanato em lã produzido em Caçapava do Sul, na região pampeana do Rio Grande do Sul, o estado mais meridional do Brasil, constatou que a produção artesanal das peças em lã, historicamente presente no Estado devido às suas condições climáticas, vem recebendo alterações estéticas a partir das interpretações das artesãs dos exemplares em lã encontrados nas revistas de moda e na internet. Para as artesãs envolvidas, as peças confeccionadas na atualidade são mais atrativas para os consumidores em comparação às do passado (Vargas, 2016), constatação que evidencia nelas o desejo de participar dos circuitos de circulação e consumo simbólico mesmo que seja por meio da reprodução de padrões estéticos globalizados. 
A intensificação do turismo desempenha um papel relevante nesse contexto, pois como os produtos dotados de signos de identificação com os territórios vêm sendo cada vez mais valorizados nos mercados propiciados pelos fluxos turísticos, a demanda turística faz com que os artesãos passem a efetuar alterações nos artefatos para que eles se tornem competitivos no mercado de bens simbólicos e culturais. No Brasil, uma das instituições que possui atuação nacional na produção de artesanato associada ao turismo é o Serviço de Apoio às Micro e Pequenas Empresas (SEBRAE) ${ }^{8}$. Além de publicações que visam estimular o setor, como o 'Manual para o desenvolvimento e a integração de atividades turísticas com foco na produção associada', produzido em parceria com o Ministério do Turismo (Brasil, 2011 ), a instituição atua no sentido de prover capacitação para os artesãos e interações com designers com o intuito de aprimorar a inserção da produção nos mercados. Porém, a atuação do SEBRAE no artesanato tem sido alvo de controvérsia', pois, sendo sua base de atuação o empreendedorismo e a ampliação de mercados, as ações promovidas tendem a priorizar o ponto de vista econômico (Belas, 2012). Contudo, é importante ressaltar que - SEBRAE detém papel primordial na valorização e divulgação do artesanato brasileiro, sendo, como ressaltado por Borges (2011), a organização que obteve maior amplitude de ação entre as envolvidas com o artesanato no país.

Entre as ações promovidas pelo SEBRAE no artesanato da região Sul do Brasil, destaca-se o Projeto Artesanato do Mar de Dentro, realizado entre 2006 e 2015 no território Costa Doce, no litoral sul do Rio Grande do Sul. A Costa Doce se destaca pela fauna e flora características e por sua relevância histórica para a formação do Estado, elementos que vem sendo mobilizados em esforços de construção e projeção identitária em andamento no território. O Projeto tinha como objetivo ampliar a produção e comercialização de produtos artesanais, gerando incremento de renda para os artesãos ao mesmo tempo em que contribuía para reforçar a imagem do território. As ações do Projeto incluíram oficinas de criação e gestão que serviram de apoio para a formalização de três grupos de artesanato identitário: Bichos do Mar de Dentro, Redeiras e Ladrilã.

\section{Artesanato do Mar de Dentro}

O território denominado Costa Doce inicia no Lago Guaíba e se estende em faixa junto ao litoral até o sul do Estado do Rio Grande do Sul, sendo composto por cerca de 30 municípios que circundam o maior complexo lagunar da América Latina, denominado de Mar de Dentro: são mais de 30 lagoas e incontáveis banhados, com destaque para o Parque Nacional da Lagoa do Peixe, a Lagoa dos Patos e a Lagoa Mirim. O território compõe - Mapa do Turismo Brasileiro elaborado pelo Ministério do Turismo e sua identidade tem sido apresentada como um potencial mobilizável em estratégias de valorização produtiva como suporte ao desenvolvimento mediante o processo de reconversão, ou seja, busca-se

8 Entidade privada sem fins lucrativos que atua em todo o território nacional como agente de capacitação e de promoção do empreendedorismo.

9 Ver Canani (2008); Borges (2011); Belas (2012). 
reconverter o patrimônio cultural local para reinseri-lo em novas condições de produção e mercados. Neste processo, as especificidades culturais são valorizadas e utilizadas como instrumento para impulsionar o comércio e o turismo.

O Projeto Artesanato do Mar de Dentro, iniciado em 2006 pelo SEBRAE de Pelotas, tinha como objetivo fortalecer os núcleos de artesanato do território Costa Doce por meio do apoio à criação, produção e venda de produtos diferenciados, com vinculação identitária. Durante o período de ação do Projeto foram apoiados três grupos, posteriormente formalizados como associações de artesãos ${ }^{10}$, organizados em torno do trabalho coletivo ${ }^{11}$ autogerido, cujos artefatos remetem a diferentes aspectos identitários do território Costa Doce. Os artesãos do Bichos do Mar de Dentro confeccionam artefatos retratando a iconografia local, mais especificamente a fauna característica do território. As artesãs do grupo Redeiras produzem artesanato utilizando como matéria-prima local subprodutos da pesca, como redes, escamas e couro de peixe. O grupo Ladrilã, por sua vez, utiliza a lã natural em produtos que buscam retratar a cultura do território ${ }^{12}$.

Os artesãos envolvidos no Projeto possuíam uma produção prévia, porém as técnicas e motivos utilizados não eram considerados tradicionais nem signos de distinção territorial. Ao integrarem o Projeto, passaram a receber apoio e incentivo para a produção de artefatos identitários, incluindo a realização de oficinas com designers com o intuito de desenvolverem novas linhas de produtos que fossem vinculados ao território, seja a partir das técnicas utilizadas ou dos motivos retratados. Ou seja, os artefatos sofreram hibridações para simbolicamente se vincularem a aspectos identitários da Costa Doce, inserindo, assim, os artesãos no circuito turístico em consolidação no território.

"O artesanato da região era aquilo que é em tudo que é lugar. Era o artesanato que tu vê que eles copiam das revistas, que na verdade fica tudo muito igual, enfim, e eles começaram a se dar conta disso quando a gente começou a trabalhar e mostrar pra eles o quanto podia ter um valor muito maior se eles trabalhassem alguma coisa que tivesse identidade desse lugar" (J. gestora do Projeto Artesanato do Mar de Dentro, 2015).

Como explicitado pela gestora do Projeto, para que os artesãos se insiram na arena de produção-circulação-consumo de artefatos culturais propiciada pelos fluxos turísticos, sua prática é submetida a estratégias discursivas e imagéticas. O passado passa a ser reencenado e tradições são (re)inventadas em um processo de tradução cultural (Bhabha, 2013) que potencializa sua vinculação com o território. A narrativa é utilizada para reforçar o simbolismo que acompanha os produtos (Stewart, 1993). Previamente à ação do SEBRAE, os artefatos eram comercializados especialmente pelo seu valor de uso, seja adornar, agasalhar ou presentear. Posteriormente, quando designers passam a atuar junto aos grupos, as

10 De acordo com a Portaria n. 1.007 (2018), associações de artesãos são instituições de direito privado, sem fins lucrativos, constituídas com o objetivo de defender e zelar pelos interesses de seus associados.

11 Para alguns produtos, o processo de trabalho é coletivo e para outros é parcialmente coletivo.

12 Quando as entrevistas foram realizadas, os grupos Bichos do Mar de Dentro e Ladrila eram compostos por ampla maioria de mulheres, e o grupo Redeiras era formado somente por artesãs. 
peças se tornaram signos no mercado de bens simbólicos. De bijuterias, ganharam o status de biojoias. De artesanato, passaram a peças de arte. Esta ressignificação pode ser confirmada nos textos encontrados nas páginas de divulgação dos grupos na internet:

A Coleção Redeiras apresenta produtos produzidos pelas mãos de um grupo de artesãs da Colônia de Pescadores São Pedro - Z-3, localizada no extremo sul do Brasil. Elas transformam lixo em arte, reciclando escamas de peixe, redes de pesca e couro de peixe (Redeiras, n.d.).

A lã é arte. Graças às técnicas utilizadas no tecido de lã, pode adquirir as mais diversas formas estéticas, transformando-se em verdadeiras peças de arte (Ladrilã, n.d.).

A identificação com o território facilitou para que os artesãos conseguissem um espaço para a comercialização do seu artesanato no recém-reformado Mercado Central de Pelotas. Porém, além de comercializarem seus produtos no Mercado Público, onde podem tratar diretamente com o público consumidor, os artesãos também participam de feiras especializadas em artesanato, onde podem negociar com lojistas de diferentes partes do Brasil, e até exterior, que revendem seus produtos.

"Quando a gente foi pra Minas [Gerais] a gente abriu muitas portas, a gente conseguiu quatro lojistas, e a gente conheceu uma moça da França, aí a gente exportou, a gente fez a nossa primeira exportação, que foi da biojoia. [...] Ficamos muito faceiras, muito contentes. E a gente tem lojistas que nos encomendam todo o ano, todo o ano, agora a gente tá mandando uma [encomenda] pra Fortaleza, que é da bolsa Lagoa dos Patos, que é o nosso carro chefe, que ganhou o prêmio da Moda Casa [Casa Museu Objeto Brasileiro] lá em São Paulo." (F., artesã do grupo Redeiras, 2015).

A artesã fez questão de ressaltar a crescente demanda que os artefatos vêm recebendo, especialmente após um exemplar ter sido contemplado com um prêmio de abrangência nacional, evidenciando que seu orgulho em relação à prática artesanal está diretamente relacionado com o sucesso comercial das peças, discurso que está em consonância com a posição doSEBRAE. Para a entidade, o êxito das coleções desenvolvidas é medido pela abrangência mercadológica das peças, catalisada pela aproximação com o design e, consequente, a inserção do artesanato no mercado ditado pela moda (Mello, 2016). Em uma sociedade de consumidores, a instabilidade dos desejos e a insaciabilidade das necessidades resultam na tendência ao consumo instantâneo de novidades logo descartáveis (Bauman, 2008). Desse modo, quanto mais o artesanato está inserido nos circuitos comerciais, mais a novidade se torna um requisito imprescindível para manter os consumidores interessados nos produtos.

"Porque a feira de São Paulo mesmo que a gente foi, a última que a gente foi, a gente levou os mesmos produtos que a gente levou na primeira. E aí o lojista vai querendo novidade. Aí ele disse, 'ah, qual é a novidade?' 'A novidade é a cor', eu disse pra ele, 'a gente tá tingindo em três tons agora, a gente tingia no primeiro uma cor só, aí a gente começou a tingir em dois tons, e agora a gente tá tingindo em três tons', eu disse pra ele. Fizemos uma bolsa menor, porque às vezes as mulheres queriam a Lagoa dos Patos menor, com fecho, a gente fez uma menor com fecho. [...] Então ficou, mas novidades mesmo a gente não tem, né." (F., artesã do grupo Redeiras, 2015). 
O artesanato produzido pelos artesãos dos grupos da Costa Doce está em íntima relação com o mercado, como uma das artesãs confidenciou, quando não há demanda, não há estímulo para continuar a produção. A dimensão econômica, portanto, é importante para assegurar a continuidade da prática artesanal como um meio de subsistência para os artesãos. Porém, Belas (2012, p. 124) ressalta que a negociação em termo de "volume e prazo das encomendas é fundamental para evitar demandas que ultrapassem a capacidade de escala e de ritmo temporal dos produtores e respeitem as condições socioambientais de produção". Essa negociação pode ser facilitada quando os artesãos possuem apoio institucional que os preparem para essas situações, como nos casos vislumbrados na Costa Doce, onde as artesãs relataram que os lojistas seguidamente tentam encomendar quantidades excessivas de peças, incompatível com o tempo demandado para a confecção artesanal que é, por natureza, muito mais lenta que a industrial. Elas ressaltaram que, muitas vezes, o que os lojistas querem é o 'industrianato', um misto de indústria e artesanato que resulta em artefatos idênticos produzidos em grande escala, com utilização de moldes e formas em máquinas e equipamentos de reprodução.

"Quando eu tive em São Paulo teve uma lojista que sentou comigo e disse: 'eu quero 600 bolsas pra daqui a um mês'. Eu disse pra ela: 'eu não vendo 'industrianato', eu vendo artesanato. [...] 'uma bolsa leva um dia pra ficar pronta, eu não posso te entregar 600 bolsas em um mês'. Aí ela disse: 'mas eu queria uma tiragem grande porque eu vou pra França'. Eu digo: 'eu queria muito fechar o contrato contigo, porque eu dependo do artesanato, só que eu faço artesanato, eu não posso dizer que a minha bolsa preta e vermelha vai ficar preta e vermelha da mesma tonalidade que tu quer. Uma peça é única." (F., artesã do grupo Redeiras, 2015).

As artesãs do Projeto Artesanato do Mar de Dentro compreendem que o que diferencia o produto que elas comercializam é a manualidade do processo, fator que impossibilita a criação de muitas peças em um espaço de tempo reduzido. Esse fato vem sendo constantemente ressaltado aos lojistas, que seguidamente solicitam pedidos de grande quantidade de peças, incompatíveis com o processo de produção artesanal.

A valorização econômica dos artefatos, alavancada pelos processos de hibridação promovidos pela interação com o SEBRAE, foi o aspecto positivo mais evidenciado pelas artesãs entrevistadas, especialmente as do grupo Redeiras, cuja renda familiar até então advinha exclusivamente da atividade pesqueira, que vem gerando um baixo retorno econômico devido às sucessivas safras desfavoráveis.

"Porque a gente se preocupa, quando não tem peixe não tem como fazer feira de peixe. Esse ano mesmo a gente tá vindo de duas safras frustradas de camarão. Agora a nossa renda é quase compatível com a do marido. De primeiro não era. De primeiro a gente vendia artesanato assim, pra uma vizinha, uma conhecida, para uma pessoa que queria um produto diferente. Lá de vez em quando, uma vez por mês, a gente vendia artesanato. Hoje em dia não, hoje em dia dá pra se dizer que a nossa renda é quase igual à do marido." (F., artesã do grupo Redeiras, 2015). 
As mudanças positivas ressaltadas na recorrência aos enunciados do discurso ambientalista também foram comentadas por uma das artesãs entrevistadas. A utilização dos resíduos da pesca como matéria prima para o artesanato, fez com que aqueles diminuíssem consideravelmente e a maior valorização dos seus produtos artesanais no mercado fez com que materiais antes percebidos como resíduos de baixo valor, como as redes e as escamas, passassem a ser considerados matérias-primas valiosas, contribuindo para aumentar o sentimento de autoestima pelo pertencimento a uma colônia de pescadores.

"Sempre quando a gente fala pras pessoas a gente quer falar na mudança que teve na Z3, na colônia. Porque a gente sempre explica muito que a pele que a gente tira, que a gente tá fazendo aquela bolsa ali, que eu tô vendendo aquela bolsa, não tá dentro da lagoa, não tá rolando. A escama de peixe não tá polvindo a beira da praia que os veranistas vêm tomar banho. Aquela rede não tá mais sendo queimada né, ela não tá mais sendo jogada no fundo da lagoa, que mata os peixes, mata outros bichos que vem, né? Então, a gente sempre fortalece isso que essa bolsa que tu tá levando tá ajudando, um lugarzinho lá pequeninho né, mas tá." (F., artesã do grupo Redeiras, 2015).

Portanto, o fato dos artefatos confeccionados pelo Projeto Artesanato do Mar de Dentro evidenciarem elementos identitários do território contribuiu para aumentar o sentimento de orgulho entre os artesãos, pois se sentem contribuindo para a valorização do território do qual fazem parte, o que corrobora o posicionamento de Borges (2011), que entende que os produtos que trabalham as identidades culturais fazem com que os artesãos envolvidos tenham maior estima em relação às suas origens e ao seu cotidiano, aumentando seu sentido de pertencimento.

"Até vou te dizer, até no sentido de tu te sentir [...] diferente, e faz bem pra ti que tu tá falando aquilo ali, tu tem segurança daquilo que tu tá falando e que é uma coisa que tu vivencia. Como é que eu vou te explicar, eu antes nem dava bola, eu via os passarinhos, 'ah passarinho', agora não, agora eu passo, lá, eu moro lá na praia, né, lá no Laranjal, eu passo, 'olha!', aquilo me dá uma ternura de ver, a noivinha na cerquinha. Ver o biguá, [...] e eu conheço, e eu conheço graças ao artesanato. Isso eu acho muito legal. E isso não é só eu, tu nota nas pessoas que é assim, aqui mesmo vem uns sabiás e uns, aqueles amarelinhos, bem-te-vi, 'ah! Olha que bonitinho!' É, a gente fica, parece assim que eles são, fazem parte da gente mesmo, e isso eu acho que é o mais legal, sabe?" (M., artesã do grupo Bichos do Mar de Dentro, 2014).

No atual cenário global, onde as relações sociais são cada vez mais mediadas por signos (Lash e Urry, 2002), produtos assinados por designers renomados conseguem maior visibilidade mercadológica e, consequentemente, a demanda pelos produtos da coleção aumenta. No caso do Artesanato do Mar de Dentro pudemos constatar que, ao mesmo tempo em que expressavam satisfação pelo prestígio que os produtos alcançaram com a ajuda do designer, o fato de alguns consumidores procurarem o artesanato produzido pelo grupo somente pela assinatura do designer, também era motivo de algum ressentimento por parte das artesãs entrevistadas.

"E o interessante, o importante do designer é que o designer vende. A gente não tinha esta noção no início, de que, por exemplo, uma coleção assinada por um designer tem um valor. Nas feiras que a gente vai pra São Paulo, pra Belo Horizonte, essas feiras aí fora, o pessoal chega já dizendo assim 'ah, esse é o trabalho de fulano de tal' 
e muitas vezes compram porque é do fulano de tal. Se tu tiver um trabalho dele, ou delas, tu tem um status. Isso a gente não tinha essa noção. E pra gente é bom, porque a gente vende, por outro lado, não sei sabe se era isso que a gente queria no artesanato, vender pelo nome. A gente vende pela qualidade, pelo produto, né. Pra nós o que interessa é isso. Mas é importante que a gente tenha, a pessoa desenvolveu o trabalho, é a valorização do trabalho daquela pessoa, daquele profissional que nos ajudou a desenvolver." (A., artesã do grupo Bichos do Mar de Dentro, 2015).

Identificamos no caso do Projeto Artesanato do Mar de Dentro um sentimento de ambivalência entre a vantagem comercial trazida pela ação do designer e a desvantagem percebida no fato do grupo ser reconhecido mais pelo nome do designer do que pela qualidade dos artefatos confeccionados. Esse fato contribuiu para que houvesse um movimento em busca de maior independência dos designers no que diz respeito ao desenvolvimento dos produtos. A partir da interação diária com o público consumidor, os artesãos começaram a criar novos artefatos e se sentiram confiantes para produzir o que acreditavam ser adequado para o grupo, independente da opinião dos designers. Este fato demonstra a conquista gradual de maior autonomia por parte dos artesãos frente aos atores institucionais, e pode ser corroborado pela seguinte fala de uma das artesãs:

"Há horas queria fazer tipo um terço, um terço de bolinhas, aí a gente levou pra designer a ideia e ela disse: 'ah, não, já parte pro lado religioso, não sei o que'. Não gostou da ideia, não vamos colocar. A gente fez pra loja, o terço, e foi super bem aceito, vendido, ficou bonito, e agora nessa última feira eu levei, e a gente teve um monte de encomenda. Então são coisas assim, que as vezes o designer não aprova e a gente termina no dia a dia de coisas que pedem pra fazer e termina vendendo super bem" (T., artesã do grupo Ladrilã, 2014).

Se, segundo Foucault (1991), o exercício do poder consiste em conduzir condutas e em condicionar possibilidades, o caso em questão é ilustrativo da relação de poder existente entre artesãos e designers que, assim como a hibridação, é estabelecida por meio de processos indissociáveis de dominação, tensão e resistência (Canclini, 2013).

A partir da análise que empreendemos se torna possível afirmar que os artesãos estão conscientes do potencial que o artesanato, enquanto representação identitária dos territórios, pode desempenhar nos circuitos de circulação e consumo simbólico. Porém, também estão cada vez mais cientes dos limites do sentido histórico e contextual da prática artesanal. Na contemporaneidade, frequentemente os significados simbólicos dos artefatos são produzidos dentro do terceiro espaço, em estreita relação com as práticas discursivas e, assim como as identidades, são temporais e relacionais. Nesse contexto, as práticas de hibridação e tradução cultural têm permitido aos artesãos a integração dos seus valores e formas de expressão em universos e códigos simbólicos diversos, ou seja, as ações orientadas à ampliação de mercados se mostram relevantes para a manutenção do artesanato enquanto representação identitária dos territórios, porém os artesãos devem pleitear o "controle econômico e cultural da sua produção e de todas as instâncias onde ela pode ser refuncionalizada e ressignificada" (Canclini, 1983, p. 110), evitando-se, assim, a dependência de padrões técnicos definidos por terceiros. 


\section{Considerações finais}

O contexto global contemporâneo é marcado por contatos culturais cada vez mais frequentes, possibilitando trocas de experiências e visões de mundo entre civilizações e culturas até então distantes. Canclini (2013) utiliza a noção de hibridação para se referir a essa nova situação intercultural, onde práticas que existiam de forma separada se combinam para gerar novas, resultando no que Bhabha (1990) denominou de terceiro espaço. As tecnologias de informação e comunicação e os crescentes fluxos turísticos nos territórios potencializaram as hibridações na prática artesanal, cujos significados são cada vez mais representativos de uma tradução cultural.

Com a crescente valorização do artesanato no circuito de consumo cultural, narrativas passaram a ser (re)criadas e materializadas em novas formas de fazer artesanais. No caso do Projeto Artesanato do Mar de Dentro, os artefatos comercializados foram desenvolvidos em oficinas comandadas por designers, fato que evidencia o caráter híbrido do artesanato produzido no território, tendo sido deliberadamente projetado de modo a que faça referência a elementos identitários previamente selecionados. Os processos de hibridação impactaram positivamente a situação socioeconômica dos artesãos envolvidos, pois resultaram em maior visibilidade e prestigio aos artefatos por elas produzidos, permitindo a manutenção das técnicas artesanais na atualidade, mesmo que em um estado alterado da tradição.

Em consonância com a posição de Canclini (2008), a hibridação promovida pelo SEBRAE no artesanato da Costa Doce, e favorecida pelos crescentes fluxos turísticos no território, não é um simples processo de homogeneização, mas de confrontação e diálogo, de resistência e tradução. O artesanato produzido no território já estava subordinado aos mercados antes da ação do SEBRAE, pois conforme relatado por uma das artesãs, quando não há demanda, não há produção. A adesão dos artesãos aos grupos criados pelo Projeto Artesanato do Mar de Dentro ocorreu muito em função das possibilidades mercadológicas que seriam abertas a partir do apoio institucional promovido pelo SEBRAE. Apesar de vislumbrar tensões visando à subordinação dos repertórios estéticos dos artesãos aos padrões de um circuito de circulação e consumo simbólico, percebemos indícios de um processo de aquisição de poder por parte dos artesãos, como ilustram as ações de enfrentamento aos atores institucionais, como o caso da artesã que expôs para comercialização um artefato por ela criado, mesmo após ter sido aconselhada a não fazê-lo pela designer que prestava consultoria ao grupo. Como o produto teve uma boa aceitação por parte dos consumidores, a artesã se sentiu estimulada a continuar criando produtos que possam não estar em sintonia com a especificação estética proposta pela designer, contribuindo positivamente para o processo de autonomia criativa dos artesãos.

A valorização do artesanato como expressão da identidade dos territórios busca um equilíbrio entre a concepção "romântica, conservadora, que enxerga apenas a questão cultural, ou meramente estética, e se consagra a vigiar as tradições, embalsamando os desenhos e as técnicas" e "o tecnocratismo desenvolvimentista", que propõe a modernização 
excessiva da produção artesanal, ou simplesmente a sua abolição (Canclini, 1983, p. 138). Portanto, a inserção de modificações na cadeia produtiva do artesanato com esse fim pode ser vista como uma opção para a manutenção da prática artesanal enquanto alternativa econômica não dissociada do aspecto simbólico, desde que assimilada e dirigida pelos artesãos.

Entendemos, por fim, que no contexto contemporâneo o artesanato não conseguirá subsistir com a autonomia pretendida por alguns antropólogos ou folcloristas, porém, também não é imprescindível que se torne mero apêndice atípico do circuito do atual estágio do capitalismo (Canclini, 1983). Como ressaltado por Paz (2015), é inegável o valor social desempenhado pelo artesanato, sendo tanto uma fonte potencialmente importante de geração de emprego e renda; quanto um veículo renovado de expressões culturais.

\section{Referências}

Abramovay, R. (2003). O futuro das regiões rurais. Porto Alegre: Ed. UFRGS.

Asega, S., Bhabha, H. K., Bordowitz, G. B., Kee, J., Kuo, M., Kurian, A., \& Satterwhite, J. (2017). Apropriação cultural: uma mesa redonda. PORTO ARTE: Revista de Artes Visuais, 22(37), 1-24. Recuperado de https://www.seer.ufrgs.br/PortoArte/article/viewFile/80138/47006

Albino, C. (2017). Design e techne para a valorização da identidade do território. Em Krucken, L., Mol, A. e Luz, D. (Orgs.). Territórios criativos: design para a valorização da cultura gastronômica e artesanal (pp. 29 - 46). Belo Horizonte: Editora Atafona.

Baudrillard, J. (2009). O sistema dos objetos. São Paulo: Editora Perspectiva.

Bauman, Z. (2008). Vida para consumo. Rio de Janeiro: Jorge Zahar Ed..

Beired, J. L. B. e Barbosa, C. A. S. (Orgs.) (2010). Política e identidade cultural na América Latina. São Paulo: Cultura Acadêmica.

Belas, C. A. (2012). Indicações geográficas e salvaguarda do patrimônio cultural: artesanato de capim dourado Jalapão-Brasil (Tese de Doutorado). Programa de Pós-Graduação em Desenvolvimento, Agricultura e Sociedade, Universidade Federal Rural do Rio de Janeiro, Rio de Janeiro, Brasil.

Benjamin, W. (1987). Magia e técnica, arte e política: ensaios sobre literatura e história da cultura. São Paulo: Editora Brasiliense.

Bernd, Z. (2004). O elogio da crioulidade: o conceito de hibridação a partir dos autores francófonos do Caribe. Em Abdala Jr., B. (Org.). Margens da cultura: mestiçagem, hibridismo e outras misturas (pp. 99 - 11 1). São Paulo: Boitempo.

Bhabha, H. (1990). The Third Space. Em Rutherford, J. (Org.). Identity: Community, Culture, Difference (pp. 207 - 221). London: Lawrence and Wishart.

Bhabha, H. (2013). O local da cultura. Belo Horizonte: Editora da UFMG.

Black, A. e Burisch, N. (2010). Craft hard, die free: radical curatorial strategies for craftivism in unruly contexts. Em Adamson, G. The craft reader. Oxford: Berg.

Borges, A. (2011). Design + artesanato: o caminho brasileiro. São Paulo: Terceiro Nome.

Borges, A. (2020). A valorização do "feito à mão" no contexto internacional. [Reportagem Artesol]. Recuperado de https://artesol.org.br/conteudos/visualizar/A-valorizacao-do-feito-a-mao-no-contexto-internacional

Brandão, C. (2007). Territórios com classes sociais, conflitos, decisão e poder. Em Ortega, A. C. e Almeida Filho, N. (Orgs.) Desenvolvimento territorial, segurança alimentar e economia solidária (pp. 39 - 61). Campinas: Alínea Editora.

Brasil. Ministério do Turismo. Serviço de Apoio às Micro e Pequenas Empresas. (2011). Manual para o desenvolvimento e a integração de atividades turísticas com foco na produção associada. Brasília: Ministério do Turismo. 
Canani, A. S. K. B. (2008). De Bonecas, Flores e Bordados: Investigações Antropológicas no Campo do Artesanato em Brasília (Tese de Doutorado). Programa de Pós-Graduação em Antropologia Social, Universidade de Brasília, Brasília, Brasil.

Canclini, N. G. (1983). As culturas populares no capitalismo. São Paulo: Brasiliense.

Canclini, N. G. (2008). Consumidores e cidadãos: conflitos multiculturais da globalização. Rio de Janeiro: Editora UFRJ.

Canclini, N. G. (2013). Culturas híbridas: Estratégias para entrar e sair da modernidade. São Paulo: Editora da Universidade de São Paulo.

Castells, M. (1999). O poder da identidade. São Paulo: Paz e Terra.

D'ávila, J. S. (1983). O artesão tradicional e seu papel na sociedade contemporânea. Em Ribeiro, B. et al. O artesão tradicional e seu papel na sociedade contemporânea (pp. 167 - 212). Rio de Janeiro: Funarte/Instituto Nacional do Folclore.

Escuela de Diseño. ([20--]). Programa de Artesanía. Recuperado de http://diseno. uc.cl/lineas-investigacion/lineas-de-investigacion/programa-de-artesania

Favareto, A. S. (2015). Uma década de experimentações e o futuro da política de desenvolvimento territorial rural no Brasil. Em Grisa, C. e Schneider, S. (Orgs.). Políticas públicas de desenvolvimento rural no Brasil (pp. 261 - 278). Porto Alegre: Editora UFRGS.

Ferreira, J. M. C. (1983). Artesanato, cultura e desenvolvimento regional: um estudo de campo e três ensaios breves. Vila da Maia: Gráfica Maiadouro.

Foucault, M. (1991). Vigiar e Punir. Petrópolis: Vozes.

Foucault, M. (1995). Microfísica do poder. Rio de Janeiro: Graal.

Froehlich, J. M. (Org.) (2012). Desenvolvimento Territorial - Produção, identidade e Consumo. ljui: Edunijuí.

Haesbaert, R. (1997). Des-territorialização e identidade: a rede gaúcha no Nordeste. Niterói, RJ: Eduff.

Hall, S. (1999). Identidade cultural na pós-modernidade. Rio de Janeiro: DP\&A.

Harvey, D. (2012). Condição pós-moderna: uma pesquisa sobre as origens da mudança cultural. São Paulo: Loyola.

Hobsbawm, E. (2012). Introdução: A invenção das tradições. Em Hobsbawm, E. e Ranger, T. (Orgs.). A invenção das tradições (pp. 7 - 25). São Paulo: Paz e Terra.

Kern, D. (2004). O conceito de hibridismo ontem e hoje: ruptura e contato. MÉTIS: história \& cultura, 3(6), 53-70. Recuperado de http://www.ucs.br/etc/revistas/ index.php/metis/article/viewArticle/1158

Kopytoff, I. (2008). A biografia cultural das coisas: a mercantilização como processo. Em Appadurai, A. (Org.) A vida social das coisas: as mercadorias sob uma perspectiva cultural (pp. 89 - 123). Niterói: Editora da Universidade Federal Fluminense.

Ladrilã. (n.d) História. Recuperado de http://www.ladrila.com.br

Lash, S. e Urry, J. (2002). Economies of signs and space. London: SAGE Publications.

Leite, R. P. (2005). Modos de vida e produção artesanal: entre preservar e consumir. Em Sampaio, H. (Org.). Olhares itinerantes: reflexões sobre artesanato e consumo de tradição (pp. 27 - 41). São Paulo: Artesanato Solidário.

Lima, R. G. (201 1). Artesanato em debate: Paulo Keller entrevista Ricardo Gomes Lima. Revista Pós Ciências Sociais, 8 (15), 187-210. Recuperado de http:// www.periodicoseletronicos.ufma.br/index.php/rpcsoc/article/view/593/339

Mello, C. I. de. (2016). Território feito à mão: Artesanato e identidade territorial no Rio Grande do Sul (Tese de Doutorado). Programa de Pós-Graduação em Extensão Rural, Universidade Federal de Santa Maria, Santa Maria, Brasil.

Mello, C. I. de; Froehlich, J. M. (2015). Artesanato enquanto expressão de identidade territorial: o caso da Costa Doce. Anais do $53^{\circ}$ Congresso da Sociedade Brasileira de Economia, Administração e Sociologia Rural, João Pessoa.

Mello, C. I. de; Froehlich, J. M. (2016). Artesanato tradicional rural e desenvolvimento territorial no Brasil: uma análise do estado da arte. Antropolítica: Revista Contemporânea de Antropologia, 39 (2), 150-182. Recuperado de http:// www.revistas.uff.br/index.php/antropolitica/article/view/222/pdf

Mignosa, A. e Kotipalli, P. (2019). Introduction. Em Mignosa, A. e Kotipalli, P. (Eds.). A cultural economic analysis of craft. Cham, Suiça: Palgrave Macmillan.

Noronha, R. G. (Org.) (2011). Identidade é valor: as cadeias produtivas do artesa- 
nato em Alcântara. São Luís: EDUFMA.

Organização das Nações Unidas para a Educação, a Ciência e a Cultura [UNESCO]. (2017). Artesanía y Diseño. Recuperado de http://www.unesco.org/ new/es/culture/themes/creativity/creative-industries/crafts-and-design.

Organização das Nações Unidas para a Educação, a Ciência e a Cultura [UNESCO]. (2005). Encuentro entre Diseñadores y Artesanos. Recuperado de http:// unesdoc.unesco.org/images/0014/001471/147132s.pdf

Ortiz, R. (2013). Imagens do Brasil. Sociedade e Estado, 28 (3), 609-633. Recuperado de https://periodicos.unb.br/index.php/sociedade/article/view/5840/5285

Paz, E. F. de. (2015). La valorización artesana y su repercusión turística. El caso de Chile. PASOS. Revista de Turismo y Patrimonio Cultural, 13 (2), 375-393. Recuperado de https://dialnet.unirioja.es/servlet/articulo? codigo $=5089496$

Paz, O. (2006). O uso e a contemplação. Revista Raiz: Cultura do Brasil, 3. Recuperado de http://revistaraiz.uol.com.br

Portaria n. 1.007, de 11 de junho de 2018 (2018). Institui o Programa do Artesanato Brasileiro, cria a Comissão Nacional do Artesanato e dispõe sobre a base conceitual do artesanato brasileiro. Recuperado de http://www.in.gov.br/ materia/-/asset_publisher/Kujrw0TZC2Mb/content/id/34932949/do 1-20 18-0801-portaria-n-1-007-sei-de-1 1-de-junho-de-2018-34932930.

Radcliffe, S. A. (Org.). (2006). Culture and Development in a Globalizing World: Geographies, actors and paradigms. Routledge, London \& New York.

Raffestin, C. (1993). Por uma geografia do poder. São Paulo: Ática.

Redeiras. (n.d.). Coleção Redeiras. Recuperado de http://www.redeiras.com.br

Reis, José. (2015). Território e políticas do território a interpretação e a ação. Finisterra - Revista Portuguesa de Geografia, (100), 107-122. doi: 10.18055/Finis7868

Rios, J. A. (Org.). ([196-]). Artesanato e desenvolvimento: o caso cearense. CNI/ SESI.

Sack, R.D. (1986). Human territoriality: its theory and history. Cambridge: University Press.

Serviço de Apoio às Micro e Pequenas Empresas [SEBRAE]. (2019). Boletim Comércio e Serviços: Artesanatos. [Boletim SEBRAE Mato Grosso do Sul]. Recuperado de https://m.sebrae.com.br/sites/PortalSebrae/ufs/ms/artigos/boletim-comercio-e-servicos-artesanato, afb62 1600576a4 10VgnVCM 1000003b74010aRCRD\#

Soares Jr., A. e Santos, M. A. (2018). A territorialidade e o território na obra de Robert David Sack. Geografia (Londrina), 27 (1), 07-25.

Stewart, S. (1993). On Longing: narratives of the miniature, the gigantic, the souvenir, the collection. Durham: Duke University Press.

Stross, B. (1999). The Hybrid Metaphor: From Biology to Culture. The Journal of American Folklore, 112 (445), 254-267. Recuperado de https://www.jstor.org/stable/541361? seq $=1$

Vargas, D. L. de. (2016). Tecendo Tradição: artesanato e mercado simbólico em uma comunidade rural do pampa gaúcho (Tese de Doutorado). Programa de Pós-Graduação em Extensão Rural, Universidade Federal de Santa Maria, Santa Maria, Brasil.

Vives, V. de. (1983). A beleza do cotidiano. Em Ribeiro, B. et al. O artesão tradicional e seu papel na sociedade contemporânea (pp. 133 -163). Rio de Janeiro: Funarte/Instituto Nacional do Folclore.

World Crafts Council. (2012). Our vision. Recuperado de http://www.worldcraftscouncil.org/vision

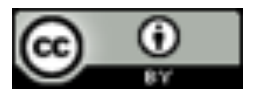

Este es un artículo de acceso abierto bajo licencia Creative Commons Reconocimiento 4.0 Internacional 